\title{
Human Dignity in the Mechanics of Claims
}

\author{
Ralf Poscher ${ }^{1}$
}

Accepted: 4 November 2021 / Published online: 29 November 2021

(c) The Author(s) 2021

\begin{abstract}
The mechanics of claims focusses predominantly on the claim to life. The claim to life is rooted in the autonomy principle, just like other specific claims. Still, the mechanics of claims does not have a systematic place for the fundamental negation of the status as an autonomous being as such. It is, however, the proctiction of the status as such, which is at the center of the protection of human dignity in German constitutional law. Looked at it from this perspective, the protection of human dignity as the protection of the status of an autonomous human being, appears to be a blind spot of the mechanics of claims. The comment attempts to show, how this blindspot leads to inconsistencies in the mechanics of claims, and how they might be ameliorated if human dignity is considered as an absolute right independent of the claims to life.
\end{abstract}

Keywords Human dignity · Absolute rights · Right to life · German constitutional · Law · German Basic law · Torture

The core of the German Basic Law's identity is its unconditional commitment to respect and protect human dignity. Historically, the aim of this unconditional commitment of the German constitution was to contrast the post-war German political order with the dehumanizing regime of National Socialism. In the German Basic Law, the guarantee of human dignity is considered an absolute right, which is not subject to weighing and balancing. ${ }^{1}$ When describing the content of this absolute guarantee of human dignity, the means principle plays an important role. According to the so-called object formula, which is inspired by the third formulation of Kant's categorical imperative, this absolute protection prohibits the state from treating a

1 BVerfGE 34, 238 (245) [1973] ; 109, 279 (312 f.) [2004]; 141, 220 (276) [2016] (for the official translation see https://www.bundesverfassungsgericht.de/SharedDocs/Entscheidungen/EN/2016/04/rs201 60420_1bvr096609en.html); Barak 2015, pp. 227-229.

Ralf Poscher

public-law@csl.mpg.de

1 Department of Public Law, Max-Planck-Institute for the Study of Crime, Security and Law, Freiburg, Germany 
person as a mere object or means. ${ }^{2}$ As to the means principle itself, both the German discourse and general human dignity discourse can learn much from Alec Walen's "Mechanics of Claims" and its intricate analysis of the means principle, and the related restricting claims principle. ${ }^{3}$ The following comment contends that the mechanics of claims can also learn from the German human dignity discourse and its use of the object formula to describe the specificity of the absolute dignity protection in German constitutional law.

According to one interpretation of the means principle under the German constitution, a violation of human dignity consists of negating the very status of an autonomous subject by another. ${ }^{4}$ The protection of human dignity is therefore relational. The inherent dignity of a human being demands respect for his or her autonomous nature by others. This respect can be expressed in different shapes and forms. It is not violated by measures that limit the exercise of autonomy. Protecting the exercise of one's autonomy involves more specific freedoms such as freedom of speech, assembly, religious beliefs, etc. It is, however, violated if the very status of an autonomous human being is negated.

The difference can be illustrated with the paradigmatic case of torture. Torture aims to circumvent the rational capacities of its victim. It tries to reduce a human being to a body of pain that reacts to purely biological triggers. The torture victim is not treated as a rational subject but as an object of physiological manipulation. It is neither the pain as such that constitutes torture, nor the infringement of bodily integrity and health, but the negation of the victim's status as an autonomous subject. This violates the basic respect that human dignity demands from us.

Violating human dignity is not directly dependent on the interests and rights that are damaged but on the disrespect for the very status of autonomous human beings. Thus, even the deliberate killing of an attacker does not have to violate her dignity. Even though the right to life has been infringed upon and being alive is a precondition for enjoying human dignity, dignity itself is not necessarily implied. The reason why dignity is not necessarily violated does not rely on forfeiture. With respect to an aggressor's right to life, it might well be that she has forfeited it by her aggression, as the mechanics of claims implies. ${ }^{5}$ But even if an aggressor has forfeited her right to life, she cannot—according to the guarantee of human dignity in the German constitution-forfeit her dignity. ${ }^{6}$ Fighting off an aggressor in a life or death fight does not negate her status as an autonomous human being. On the contrary, the aggressor

\footnotetext{
2 BVerfGE 27, 1 (6) [1969] (partial translation in Kommers and Miller 2012, pp. 356 f.); BVerfGE 115, 118 (153) [2006] (for the official translation see https://www.bundesverfassungsgericht.de/SharedDocs/ Entscheidungen/EN/2006/02/rs20060215_1bvr035705en.html); Barak 2015, pp. 235 f.

3 Walen 2019, pp. 83-99.

4 Poscher 2021a, pp. 1128 f.; for a similar position related to the fundamental status of human beings see in the philosophical discussion cp. Etinson 2020, pp. 372-374, who like others, e.g. Margalit 1996, p. 76-88, ties human dignity to the protection against humilitation but sees rightly that not every type of humilitation will affect human dignity. "Human dignity [...] is only one species of dignity, having to do with our basic status as equals in society" (p. 372).

5 Walen 2019, p. 65.

6 BVerfGE 115, 118 (153, 160 f.) [2006] (for the official translation see https://www.bundesverfassun gsgericht.de/SharedDocs/Entscheidungen/EN/2006/02/rs20060215_1bvr035705en.html).
} 
and her autonomous decisions in the conflict are taken very seriously. The life of the victim of the aggression depends on taking the aggressor and her autonomy seriously. She is fought against and perhaps even killed as an autonomous subject, albeit a dangerous and hostile one.

The forfeiture approach of the mechanics of claims suggests that the matter of permissible killing leads the mechanics of claims to focus predominantly on the claim to life. The claim to life is rooted in the autonomy principle, just like other specific claims. Still, the mechanics of claims does not have a systematic place for the fundamental negation of the status as an autonomous being as such; this is accompanied by challenges to specific claims, which are rooted in this status but are not identical to them. The protection of human dignity, as the protection of the status of an autonomous human being, thus becomes a blind spot. As the following discussion attempts to show, this leads to inconsistencies in the mechanics of claims, which might be ameliorated if human dignity in the above sense is considered as an absolute right independent of the claims to life.

In the mechanics of claims, the means principle is reconstructed via the notions of restricting claims and negative property claims. ${ }^{7}$ Restricting claims are "claims that push to restrict an agent relative to her baseline freedom and thereby also push to make others with competing restricting claims normatively worse off." ${ }^{8}$ Restricting claims are negative claims when they call for an agent not to do something and positive claims when they demand that an agent does something on behalf of a patient, i.e., somone whose welfare interests are affected by the choices of an agent. ${ }^{9}$ The claim not to have been run over by the driver of a car would be a negative patient claim. The claim would be restricting if the driver has an interest to keep driving without stopping, for example because of an important meeting.

Their positive counterparts are patient claims requiring an agent to do something on behalf of the patient. Good Samaritan laws, which require agents to help someone in distress, rest on such positive patient claims. Property claims "are claims a patient has over some item that puts it in his toolbox and outside the toolbox of others and thereby limits their basic freedom.". ${ }^{10}$ The claim not to have to allow someone to use one's car would be a property claim. The distinction between these claims is important because - as the mechanics of claims convincingly argues - there are considerable differences in weight between them. Whereas restricting negative patient claims can be outweighed by a sufficient number of comparable restricting positive patient claims, property patient claims, which are non-restricting negative patient claims, usually outweigh even larger accumulations of comparable positive patient claims, due to their importance for and the preponderance of the autonomy principle they serve. ${ }^{11}$

\footnotetext{
7 Walen 2019, pp. 83-99.

8 Walen 2019, p. 223.

9 Walen 2019, p. 222.

10 Walen 2019, p. 222.

11 Walen 2019, pp. 88 f.
} 
With these general principles in play, the mechanics of claims tries to explain our diverging intuition in the classic "trolley switch" case, on the one hand, and cases like "the massive man," on the other. In the trolley switch case, the claim of the bystander, who would have to be sacrificed by redirecting a trolley to his track in order to save five persons in the trolley's original track, is only a restrictive negative patient claim. The five could be saved without any competing claims to their five positive patient claims if the bystander were not present. Would the bystander's negative patient claim be given precedence, the five would have to die even though they could be saved if the bystander were not standing on the track. Thus, the bystander's restrictive negative patient claim comes with externalities for the five, making it weaker. It is still slightly stronger than a single positive patient claim, but it registers in the same ballpark and can be outweighed by a sufficient number of positive patient claims. Five or maybe even three seem to suffice according to most people's intuition.

In the case of the massive man, who is to be thrown in front of the trolley, his property claim outweighs the claims of the five who could be saved if he were thrown in front of the train that is hurling towards them. His property claim is very strong for two reasons: First, unlike the negative patient claim of the bystander, it does not come with externalities. It is not as if the five could be saved if he were not around. Instead, they rely on using his body, his first property, to be saved, and his body is beyond the baseline freedom of the others involved. ${ }^{12}$ The second reason why first property claims, in particular, are so strong is that they are fundamental to autonomy. If the massive man's claim to life could be outweighed by any positive patient claim, it would be difficult to imagine meaningful autonomy at all. ${ }^{13}$ Thus, property claims easily outweigh at least the usual three to five victims that could be saved by sacrificing his body.

Negative property patient claims carry great weight in the mechanics of claims. Unlike restricting negative patient claims, they cannot be easily outweighed by similar positive patient claims. Nevertheless, property claims also follow the same model as any other claim. In the mechanics of claims, two factors determine the weight of claims: first, the type of claim they belong to; second, the interest at stake. Thus, negative property patient claims are-all else equal-much stronger than restricting negative patient claims, and restrictive negative patient claims are-all else equalstronger than positive restricting patient claims. The differences in weight, however, are not linear. Whereas restrictive negative patient claims and positive patient claims are in the same ballpark, property claims are much stronger than the other two. ${ }^{14}$

In the mechanics of claims, the type of claim is at the center of the discussion; however, it does not determine the claim's strength alone. The second factor that determines the weight of a claim is the interest at stake. The weight of the interest at stake is in itself determined by two factors. There can be differences in the quality and in the quantity of interests that bring to bear on a claim's weight. In order to see

\footnotetext{
12 Walen 2019, pp. 85 f., 88.

13 Walen 2019, pp. 88-90.

14 Walen 2019, pp. 84 f.
} 
how the quality of an interest influences the weight of claims, we can hold the type of claim and the quantity of the interest fixed. In cases involving an equal number of an equal type of claim, differences between the interests' quality are decisive. If the rescuer has to choose between saving the life of victim $A$ or the car of victim $B$, the balance of the positive patient claims tilts towards A because the interest in one's life easily outweighs the interest in one's car.

The difference between the weight of an interest can also compensate the difference in weight that the type of the claim confers. Despite their towering weightconferring quality, this also holds for negative property patient claims. If the weight of the interest protected by a negative property claim is very small and the weight of the interest to be saved is much larger, a positive patient claim can prevail. If a mother has to use her neighbor's ladder to save a child from a burning building, the child's positive patient claim would empower her to use the ladder and outweighs the owner's negative property claim. This follows from the general idea underlying the mechanics of claims, for which the weight of the claim is the product of the weight-conferring power of the type of claim and the weight of the interest at stake. Thus, property claims weigh heavily, but they are not absolute and can be overridden by the even heavier weight of the quality of interests involved.

The arithmetics of weights also holds for the quantity of interests involved. In the classic trolley switch case, the bystander's negative restricting patient claim is not outweighed just by one positive restricting patient claim but, depending on one's intuition, by something between three to five positive patient claims of the persons in harm's way. Thus, even in cases in which the interest at stake has the same quality, here, the life of the patients, the slight difference in the weight of the type of claim can be overridden by the quantity of positive patient claims. In the mechanics of claims - just as in real life-the quantity of interests matters. Differences in weight that different types of claims confer can be overridden by a difference in the quantity of interests.

In principle, this should also hold for the difference in weight that property claims and positive patient claims confer. Although the mechanics of claims does not put these different types of claims in the same ballpark, even a huge difference in the weight of the type of claim should be outweighed by an even more significant difference in the weight of the interest involved. As seen above, this certainly holds true for an even more significant difference in the quality of the interests, but it should also hold true for an even larger difference in the quantity of the interest as far as the same quality of interest is concerned. Even if the weight of a negative property patient claim amounts to a bucket and the weight of a positive patient claim weighs just to a drop, the number of drops will fill the bucket at some point, and the next drop will then tip the scales towards the huge number of positive patient claims.

This is also a result that the mechanics of claims suggests. In cases such as that of the massive man, in which the lives of people in an entire city depend on throwing the massive man in front of the trolley, the mechanics of claims suggests that the positive patient claims-despite their individual, more inferior weight-can 
outweigh the negative property patient claim of the massive man. ${ }^{15}$ This seems only natural, given the way the mechanics of claims is set up as a system of weighing claims, the weight of which is determined by the type of claim and the quality and quantity of the interests involved. Even though this is the result that the mechanics of claims suggests, it only does so by stipulating a breakdown in the space of rights.

The mechanics of claims does not simply underwrite the result that seems to follow seamlessly from its internal logic. It instead entertains the thought that these cases lead to a breakdown in the system of rights. As Walen maintains, "the aspiration of the space of rights to harmonize competing claims while respecting the three foundational principles of rights breaks down.".16 But why would such cases imply a breakdown, even though the mechanics of claims produces the suggested result by simply following its internal logic and its attribution of weights?

Walen answers that the breakdown is due to the weight of the infringement of the autonomy interest that is connected with the massive man's life.

A conflict can arise if the demands of the welfare principle become irreconcilable with the demands of the autonomy principle. The latter implies that the space of rights cannot demand that an agent treat herself primarily or fundamentally as a tool for the welfare of others; she may be required to make small sacrifices for others, but there is a limit to the size of the sacrifice that can be demanded consistently with the premise that her life is fundamentally hers to live. Likewise, as property claims represent the patient analogue of this limit of the autonomy principle, there is a limit to how much can be done to use another as a tool if she is merely trying to live her own life, has done nothing to assume special duties to others, and her patient-claims impose no 'externalities' on the welfare of others. ${ }^{17}$

Even though I agree with the substantial point that a patient's autonomy bars her from being used as a tool, it is far from clear why this should follow from the mechanics of claims, given the possibility to save the life, limb, and property of a vast number of patients as alluded to by Alec Walen in his ticking-bomb-type scenarios. In cases in which a person is used as a tool, there seems to be an ad hoc switch from the mechanics of claims to a special role of the autonomy. principle. It appears as if Walen wishes to capture our intuition that something is different when we use the body of the massive man, even if we do so to save thousands of lives in the city. My claim is that the conception of human dignity that underlies the absolute right in the German constitution, can serve to explain why our intuition cannot be well explained by the mechanics of claims in its current form.

The absolute guarantee of human dignity in the German constitution requires respect for the status of human beings as autonomous subjects. This status is not violated by this or that infringement of basic rights - not even by infringements of the right to life-but only if the infringement disrespects a person's very status as an autonomous subject. The negation of said status makes the cases that Alec Walen discusses in his breakdown scenarios special. They come with an infringement that

\footnotetext{
15 Walen 2019, pp. $116 \mathrm{f}$.

16 Walen 2019, pp. $116 \mathrm{f}$.

17 Walen 2019, p. 116.
} 
goes beyond the sacrifice of life. They come with a negation of the status as a human being.

The negation of this status distinguishes the scenario of the massive man categorically from the standard bystander case. Both cases are not only different concerning the weight of his property right, which can be overridden by the counterbalancing weight of a huge number of people saved and their positive patient claims. The problem is not that his property claim on his own life is infringed upon-remember, the killing as such does imply the right to life, not necessarily dignity -, but that it is done in a way that negates his status as an autonomous human being. By using the massive man as an inanimate object, he is treated as a mere means. He is used like any other weighty object, like a large log or a pole, would be used. By using him in this way, his status as an autonomous subject is negated. The negation of this status sets cases like that of the massive man apart from the bystander scenario. It is this disrespect for his human dignity that cannot be tabulated in the mechanics of claims, which focuses predominantly on the claims to life. Thus, it is the violation of human dignity that leads to a breakdown of the mechanics of claims.

The mechanics of claims intricately tracks the logic with which the different interests that are grounded in our autonomy are weighed. It can thus explain-with great insight-how the different autonomy interests are offset against each other in the mechanics of highly differentiated types of claims. It does not have a good systematic place for the special violation of our autonomy that does not concern this or that specific autonomy interest, but our autonomy as such. This, however, is exactly what the guarantee of human dignity in the German constitution can be understood as protecting. Thus, the violation of human dignity can explain our unease in using the massive man as an inanimate object, even if the mechanics of claims shows that his specific autonomy interest in his own life, which is protected by a very weighty property claim, is outweighed by the much less weighty but much more numerous positive patient claims relating to the same specific autonomy interest. Our unease, namely why we perceive these situations as a dilemma, is not because of the breakdown of the system of rights as regards the specific autonomy interest in one's life but because of the violation of human dignity. Thus, the constructive suggestion would be to contemplate whether the mechanics of claims can integrate an absolute right protecting against the negation of the very status of an autonomous human being. The mechanics of claims already shows sensitivity to the status aspect of the autonomy principle. It elaborates on the autonomy principle as follows: "As a status, autonomy can be understood as the normative claim that an autonomous agent, in the strong sense, should be treated as such.". ${ }^{18}$ If the status thus described were not to be conceived of as a mere claim, but as an absolute right, the mechanics of claims could serve to explain why the harmony breaks down in ticking-bomb type cases, even though the property claim to one's life is outweighed by a huge number of positive patient claims. It does not break down because the property claim is outweighed but because the prevailing positive patient claims would collide with the absolute status of the right of human dignity. If one were to follow the solution

18 Walen 2019, p. 49. 
suggested for ticking-bomb type scenarios, in which using the massive man as an inanimate object could save thousands of lives, the violation of his right to dignity would explain why the system of rights would fall out of harmony. The harmony would be destroyed because his right would have to be violated in order to achieve the suggested result. Even though upgrading the autonomy status claim to an absolute right seems to explain the breakdown of the aspired harmony of rights better than the current mechanics, without such a right, I do not claim to oversee whether such an absolute right would fit within the overall mechanics of claims and its intricate details, which are so profoundly discussed in Alec Walen's book.

The mechanics of claims is not about positive law or a specific legal system. It tries to describe ethical claims and their resolution into moral rights that underlie our moral intuition about justified killings. The permissibility of actions does not have to be decided in the same way in the moral and the legal realms.

Even if there are cases for which the mechanics of claims sees a breakdown in the system of rights in the moral realm, this does not necessarily imply that there is also a breakdown in these cases in the legal realm or that the law has to come to the same result as an evaluation of the corresponding moral claims and rights.

This also seems to be the position in the mechanics of claims. Alec Walen introduced the idea of a breakdown of the harmony of rights with the example of a parent who chooses to save her child at the expense of the life of another: "one might face a deep conflict between the love and loyalty one feels for and to certain others and the demands of the balance of patient-claims. For example, a parent might feel obliged to turn a trolley away from her child onto another, even though the other has a right not to have a trolley turned onto him for the sake of one person.". ${ }^{19}$ Even though such a conflict might lead to a breakdown of the harmony of rights, it would still not follow that the law could not uphold its prohibition to kill an innocent bystander to save the life of only one other person.

This also holds true for the above-mentioned ticking-bomb type examples and the guarantee of human dignity. The law has to consider many more aspects than the mere weight of moral claims and rights. It has to take into account the institutional setting in which the rights are implemented and the implications of assigning rights within the doctrinal framework of a specific legal system. Thus, ticking-bomb scenarios do not have to be decided the same way in law as they are decided in moral theory. ${ }^{20}$ Therefore, the German guarantee of human dignity can be absolute, even if, in some cases, the harmony of moral rights might break down. This does lessen the value of the analytic power of the mechanics of claims for the law. The law has to consider the moral claims and rights the mechanics of claims so intricately portrays. However, it has to consider institutional and doctrinal issues as well, which lie beyond the ethical analysis in the mechanics of claims. ${ }^{21}$

Funding Open Access funding enabled and organized by Projekt DEAL.

\footnotetext{
19 Walen 2019, p. 115.

${ }^{20}$ For an argument for a possible divergence regarding the permissibility of preventive torture Poscher 2006, pp. 83-86; Poscher 2021b.

21 Walen 2019, p. 37.
} 
Open Access This article is licensed under a Creative Commons Attribution 4.0 International License, which permits use, sharing, adaptation, distribution and reproduction in any medium or format, as long as you give appropriate credit to the original author(s) and the source, provide a link to the Creative Commons licence, and indicate if changes were made. The images or other third party material in this article are included in the article's Creative Commons licence, unless indicated otherwise in a credit line to the material. If material is not included in the article's Creative Commons licence and your intended use is not permitted by statutory regulation or exceeds the permitted use, you will need to obtain permission directly from the copyright holder. To view a copy of this licence, visit http://creativecommons.org/ licenses/by/4.0/.

\section{References}

Barak A (2015) Human dignity: the constitutional value and the constitutional Right. CUP, Cambridge Etinson A (2020) What's So Special About Human Dignity? Philos Public Aff 48:353-381

Kommers D, Miller R (2012) The Constitutional Jurisprudence of the Federal Republic of Germany, 3rd edn. Duke Univ. Press, Durham

Margalit A (1996) The Decent Society, 2nd edn. HUP, Cambridge

Poscher R (2006) Menschenwürde als Tabu: Die verdeckte Rationalität eines absoluten Rechtsverbots der Folter. In: Beestermöller G, Brunkhorst H (eds) Rückkehr der Folter: Der Rechtsstaat im Zwielicht. Beck, München, pp 75-87

Poscher (2021a) Menschenwürde. Forthcoming. In: Herdegen M, Masing J, Poscher R, Gärditz K (eds) Handbuch des Verfassungsrechts: Eine Darstellung in transnationaler Perspektive. Beck, München, pp 1097-1158

Poscher (2021b) Human dignity as taboo. Forthcoming. In: Arel S, Cooper L, Hellmann V (eds) Human Dignity at the Thresholds. Springer, Vienna

Walen A (2019) The mechanics of claims and permissible killing in war. OUP, Oxford

Publisher's Note Springer Nature remains neutral with regard to jurisdictional claims in published maps and institutional affiliations. 